\title{
PROBLEMATIZAÇÃO DE PRÁTICAS SOCIOCULTURAIS NA FORMAÇÃO DE PROFESSORES DE MATEMÁTICA
}

\author{
Iran Abreu Mendes22 \\ Carlos Aldemir Farias da Silva 23
}

\section{RESUMO}

Neste artigo apresentamos o desenvolvimento de uma pesquisa descritiva de algumas práticas socioculturais ou atividades profissionais, para a organização de um dossiê etnográfico que constituísse a matéria básica da elaboração de propostas didáticas para as aulas de matemática, sob um enfoque indisciplinar, a partir das realidades pesquisadas. O propósito do estudo foi que o professor explorasse essas práticas na organização de múltiplas problematizações para suas aulas de matemática na educação básica. As ações operacionalizadas fizeram parte de uma pesquisa mais ampla, financiada pelo CNPq, cuja temática envolveu relações entre história, cultura, práticas sociais e Educação Matemática. Neste sentido, a criação de conexões entre matemática, sociedade, cognição e cultura, com contribuições para a formação de professores de matemática, constituiu-se em nosso fundamento teórico que se materializou na pesquisa das práticas socioculturais de alguns grupos sociais do Rio Grande do Norte e de outros estados da região Nordeste do Brasil, com vistas à produção de material de apoio para o desenvolvimento de ações formativas junto a um grupo de professores da rede pública de ensino do Rio Grande do Norte, envolvidos no projeto. Os resultados obtidos subsidiaram a elaboração de unidades básicas de problematização (UBPs) pelos professores envolvidos no projeto, conforme sugerem Miguel e Mendes (2010), visando seu uso nas escolas do ensino fundamental e médio.

Palavras-chave: Problematização. Investigação. Formação de Professores.

\section{PROBLEMATIZATION OF SOCIOCULTURAL PRACTICES IN TEACHER TRAINING IN}

\section{MATHEMATICS}

\begin{abstract}
In this article we present the development of a descriptive research of some sociocultural practices or professional activities for the organization of an ethnographic dossier which would constitute the basic material for the elaboration

22 Doutorado em Educação, pela Universidade Federal do Rio Grande do Norte. E-mail: iamendes1@gmail.com.

23 Doutorado em Ciências Sociais (Antropologia) pela Pontifícia Universidade Católica de São Paulo. Professor da Universidade Federal do Pará. E-mail: carlosfarias@ufpa.br.
\end{abstract}


of didactical proposals for mathematic classes, with an in disciplinary focus, based on the realities researched. The purpose of the study was to make the teacher to explore these practices in the organization of multiple problematizations for his/her mathematic classes in elementary education. The actions executed were part of a broader research funded by CNPQ. The National Council of Research, and the theme included relationships among history, culture, social practices and Mathematical Education. From this point of view, the creation of connections among mathematics, society, cognition and culture, with contributions for the training of mathematic teachers, was our theoretical foundation, which materialized in the research of sociocultural practices of some social groups in Rio Grande do Norte and other states in the Northeast region of Brazil, aiming at the production of supporting material for the development of formative actions with a group of teachers from the Public Educational System of Rio Grande do Norte, which was part of the project. The results obtained were the basis for the elaboration of Basic Problematization Units (BPUs) by the teachers involved in the project, according to what Miguel and Mendes (2010) suggest, aiming at their use in both Middle and High schools.

Keywords: Problematization. Investigation. Teacher Training.

\section{PROBLEMATIZACIÓN DE PRÁCTICAS SOCIO-CULTURALES EN LA FORMACIÓN DE PROFESORES DE MATEMÁTICA}

\section{RESUMEN}

En este artículo presentamos el desarrollo de una investigación descriptiva de algunas prácticas socio-culturales o actividades profesionales, para la organización de un dossier etnográfico que constituye la materia básica de la elaboración de propuestas didácticas para las clases de matemática, sobre un enfoque indisciplinar a partir de realidades estudiadas. El propósito del estudio fue que el profesor aprovechara estas prácticas en la organización de múltiples problematizaciones para sus clases de matemáticas en la educación básica. Las acciones operacionalizadas fueron parte de una investigación más amplia, financiada por el CNPq, cuya temática implicó relaciones entre historia, cultura, prácticas sociales y educación matemática. En este sentido, la creación de conexiones entre las matemáticas, sociedad, cultura y cognición, con contribuciones a la formación de profesores de matemáticas, se constituyó en nuestro fundamento teórico que se materializó en la investigación de prácticas socio-culturales de algunos grupos sociales de Rio Grande do Norte y de otros Estados en la región noreste de Brasil, con vistas a la producción de material de apoyo para el desarrollo de acciones formativas junto a um grupo de profesores de la red pública de enseñanza de Rio Grande do Norte, involucrados en el proyecto. Los resultados obtenidos subidiaram la elaboración de unidades básicas de problematización (UBPS) por los profesores involucrados en el proyecto, como sugiere Miguel y Mendes(2010), con el objetivo de su uso en las escuelas de enseñanza fundamental y media.

Palabras clave: Interrogatorio. Investigación. Formación de los Docentes. 


\section{CONSIDERAÇÕES INICIAIS}

Este artigo descreve comentários sobre parte de uma pesquisa cujo principal objetivo foi investigar práticas socioculturais desenvolvidas por grupos sociais do estado do Rio Grande do Norte, nordeste do Brasil, com vistas à construção de narrativas sobre tais práticas, de modo a oferecer possibilidades de explorações didáticas das práticas investigadas, na implementação de ações de formação dos professores de Matemática na Educação Básica na rede pública de ensino do Rio Grande do Norte (SILVA, 2013; 2014) 24 .

Nesta perspectiva, fizemos uma incursão etnográfica no campo, de modo a nos permitir compreender outras formas de aferir medidas, pesos, valores, quantidades, conjuntos, similaridades, simetrias, dissimetrias etc., pois consideramos que somente a partir de uma etnografia seria possível fazer uma melhor descrição dos conteúdos matemáticos em sala de aula, com base em uma diversidade cultural distinta, uma vez que esses conhecimentos são importantes e fazem sentido nas comunidades nas quais os sujeitos nascem e crescem. Trata-se de tomar esses conhecimentos como operadores cognitivos capazes de fazer com que façamos outra ciência escolar e como uma forma de compreender alguns dos problemas atuais da sociedade que afastam os estudantes das escolas.

\section{CULTURA, PRÁTICAS SOCIOCULTURAIS E PRODUÇÃO DE CONHECIMENTO}

Para Almeida (2010), nenhuma cultura se edifica sem a base e a argamassa do passado. O substrato de anterioridade na cultura é, entretanto, apenas uma das faces da questão e podemos dizer que esse processo se encontra razoavelmente descrito nos livros de História e Antropologia. Entretanto, é necessário assinalar, também, as características de permanência e atualidade dos saberes e conhecimentos de populações

${ }^{24}$ Pesquisa financiada pelo Conselho Nacional de Desenvolvimento Científico e Tecnológico (CNPq). 
que vivem distantes do conhecimento e dos progressos da ciência. Tais conhecimentos repassados de forma oral e experimental são responsáveis pela manutenção de centenas de grupos culturais espalhados por diversos lugares do planeta e que estão distantes da lógica do sistema mercadológico que tudo padroniza.

Em seus estudos e reflexões teóricas, Almeida (2010) assegura, ainda, que o que somos hoje não aconteceu da noite para o dia. Para ela, a fabulosa cultura e o enorme progresso científico e tecnológico dos quais nos valemos atualmente foi gestado por meio de diversas experimentações e aprendizagens das populações humanas ao longo dos séculos, uma vez que era preciso responder aos desafios do meio para garantirmos a nossa permanência na Terra. Foi dessa forma que as sociedades consolidaram os conhecimentos que, transformados e acrescidos, chegaram até os dias atuais como herança advinda de diferentes culturas.

Para Snow (1995), o termo cultura está carregado de nuanças frequentemente ambíguas e profundas. De uma parte, refere-se a desenvolvimento intelectual, desenvolvimento da mente. Mas, é preciso concebê-la também como cultivo, como "o desenvolvimento harmônico das qualidades e faculdades que caracterizam a nossa humanidade" (COLERIDGE apud SNOW, 1995, p. 86). O vocábulo é também "usado por antropólogos para denotar um grupo de pessoas que vivem no mesmo ambiente, ligadas por hábitos comuns, postulados comuns e um modo de vida comum" (idem, p. 88).

A cultura, como um conjunto de saberes, fazeres, regras, crenças, estratégias e mitos, se expressa pela diversidade, criatividade e inovação, sempre inacabada. Somos marcados pela unidade e diversidade da cultura. Somos também sujeitos que nos reorganizamos por meio da simbiose cérebro-mente-meio ambiente. Apesar de integrante do complexo sistema que constitui o meio ambiente, o homem dele se distingue pela faculdade de produção da cultura e da construção da história. A cultura é a marca da sociedade humana, ela é organizada/organizadora pela via do veículo 
cognitivo que é a linguagem, a partir do capital cognitivo coletivo dos conhecimentos adquiridos, dos saberes e fazeres apreendidos, das experiências vividas, da memória histórica, das crenças míticas de uma sociedade (MORIN, 1996).

Foi assim que o conceito de cultura acabou se tornando uma noção que habita diversos territórios do conhecimento científico, sobretudo aqueles que se agrupam na designação das ciências humanas e sociais. Circunscrita originalmente no âmbito da Antropologia, a compreensão da cultura passa a ser mediada por uma multiplicidade de conceitos que decorrem do desenvolvimento científico de cada época e dos significados distintos em função das principais matrizes teóricas das ciências sociais, expressas pelas diferentes escolas da Antropologia: evolucionismo, funcionalismo, estruturalismo e marxismo são algumas delas (FARIAS e MENDES, 2014).

Essas matrizes teóricas tecem os fios que permitem o trânsito no interior do labirinto da cultura, ao mesmo tempo em que prefiguram compromissos intelectuais e históricos distintos - em alguns casos, divergentes e antagônicos; em outros, opostos, mas complementares. É assim que o conceito de cultura tem sido tratado: ora como afastamento e dominação da natureza (evolucionismo); ora como funcionalidade das instituições e traços culturais (funcionalismo); ora como articulação das estruturas simbólicas e inconscientes (estruturalismo); ora como totalidade articulada pelas materialidades e idealidades (marxismo).

Considerando as contribuições advindas da Antropologia para a Educação como uma contribuição para a formação de professores, nosso propósito primordial é partir da ideia de cultura como um conceito transversal às diferentes áreas do conhecimento e como uma noçãoconceito importante na formação integral de qualquer profissional em Educação, na perspectiva de estabelecer melhores relações dos docentes e futuros docentes com os seus alunos, de modo a promover possibilidades para que eles se relacionem melhor com a diversidade de expressões no dia a dia da sala de aula (FARIAS e MENDES, 2014). 
Nosso ponto de partida foi apresentar aos docentes a formação do povo brasileiro a partir das três matrizes étnicas e culturais - Tupi, afro e lusa e investigar fragmentos da formação das culturas, objetivando reunir elementos para que o professor aprimore a sua prática docente. Partimos da premissa de que os professores que atuam na Educação Básica, independentemente da sua área específica (Matemática, Química, Biologia, Física, Pedagogia, História, Sociologia, etc.), necessitam conhecer e refletir sobre a nossa constituição cultural mestiça para saber lidar bem com os estudantes na escola, uma vez que vivemos em um país no qual diversas etnias estão na base da formação de sua população (RIBEIRO, 1995).

Com essa compreensão, torna-se possível enfatizarmos que somos marcados pela universalidade e pela diversidade, simultaneamente, e a singularidade de cada sujeito é o que o torna único, pois mesmo que cada um de nós esteja inserido no interior de um contexto cultural diverso marcado pelo universal, diferimos dos demais sujeitos porque temos uma história individual, familiar, inconsciente etc. Assim, é necessário que todo professor perceba que o universo da sala de aula é marcado tanto pela universalidade quanto pela diversidade e singularidades dos estudantes (FARIAS E MENDES, 2014).

A ideia de que somos portadores e produtores de cultura e, ao mesmo tempo, somos produzidos pela cultura necessita ser compreendida como algo dinâmico, de modo que cada docente possa promover em suas aulas espaços de criatividade para seus alunos. É necessário perceber o diverso como um valor significativo e não querer padronizar e/ou formatar os alunos a se expressarem da mesma maneira em sala de aula, uma vez que, para promover reservas de criatividades nos estudantes, é preciso deixá-los se expressar livremente nas atividades escolares e permitir que eles façam uso de suas experiências vividas, das situações do cotidiano, de seus valores culturais assumidos como norteadores de suas vidas (FARIAS e MENDES, 2014). 
A respeito do que entendemos como práticas socioculturais podemos destacar que são compreendidas como os saberes e fazeres de grupos sociais no interior de uma cultura específica. São desenvolvidas na busca de soluções para problemas singulares que surgem na vida das diversas comunidades humanas. Elas contribuem para vencer os desafios cotidianamente enfrentados pelas sociedades, na superação de suas dificuldades e conforme as necessidades de cada grupo. Tais práticas podem ser inovadoras ou tradicionais, conforme os interesses individuais ou coletivos, e de acordo com as características culturais do lugar nas quais são desenvolvidas (MENDES e FARIAS, 2014).

Os saberes advindos dessas práticas podem sugerir a reorganização de conteúdos mais criativos e pertinentes aos estudantes de realidades sociais nas quais o diverso é um valor maior. Essas reservas de saberes, valores, conhecimentos, técnicas de fazer e formas de viver são capazes, talvez, de se tornarem a emergência de uma nova reorganização do currículo escolar.

A escola pode, e deve, constituir-se como uma importante interface cultural entre as diversas comunidades. Ela deve assumir-se como espaço de pertencimento também das crianças e jovens de diversos contextos socioculturais e das suas famílias, respeitando e alargando as suas expectativas, como fator de sucesso. A integração das comunidades só se efetivará quando existir uma cultura de participação das comunidades na construção de um espaço partilhado, no qual possam contribuir para a construção de uma sociedade em que caibam as diferenças culturais e em que, simultaneamente, se sintam confortáveis com as cedências feitas, ou seja, um espaço que não coloque em causa os valores culturais de base das comunidades. A escola assume, assim, um importante papel, não apenas junto dos estudantes que escolariza, mas, igualmente, junto da comunidade na qual está inserida, alcançando, desta forma, as famílias desses mesmos estudantes. 


\section{A PROPÓSITO DAS ATIVIDADES HUMANAS OBJETIVAS E A MATEMÁTICA}

A relação entre a Antropologia e a Matemática não é recente. Porém, sempre que alguma área do conhecimento avança e acrescenta algo novo na história da ciência, geralmente, é porque visitou ou revisitou outras áreas, outros domínios disciplinares. A relação entre Matemática e Antropologia é um exemplo claro do que estamos falando. Diversos trabalhos produzidos na área da Educação Matemática tomam elementos da cultura e produzem novas interpretações e materiais didáticos para ensinar diferentes conteúdos que passam a fazer sentido na realidade na qual os estudantes estão inseridos. Se pensarmos que todo saber nasce dos conhecimentos locais, individuais e de experimentações, pesquisas e interrogações, veremos que a maior parte dessas interrogações tem origem em elementos da cultura, que guarda um capital cognitivo que comporta, ao mesmo tempo, elementos do universal (singular) e do diverso.

A cultura é a marca distintiva dos grupos humanos e, por essa razão, tudo o que é da ordem da ciência e do conhecimento nasce e tem sua raiz na cultura, nas especificidades das diversidades culturais. Contudo, a cultura evolui de concepção com o passar do tempo das práticas e somente a partir de novos estudos culturais de alguns grupos podemos perceber o que permanece e o que mudou para atualizar e ressignificar alguns conteúdos que são ensinados nas escolas, algumas vezes de forma descontextualizada, em comunidades em que os sujeitos utilizam conhecimentos advindos de suas práticas sociais cotidianas.

Neste sentido, Leontiev (1979) salienta que no seu desenvolvimento sócio histórico, as sociedades se apropriam dos objetos produzidos, historicamente, nas mais diversas práticas socioculturais, caracterizando assim as múltiplas formas de trabalho, contribuintes para o desenvolvimento das aptidões especificamente humanas, que se cristalizam de modo a constituir um arcabouço que denota o traço social humano. 
Ainda a esse respeito, Leontiev (1972) destaca, também, que quando a espécie humana desenvolve sua consciência a respeito dos objetos existentes no mundo, passa a se apropriar de maneira integral das criações das gerações anteriores e amplia sua capacidade de se desenvolver, ou seja, a humanidade aprende a ser humana. O autor reitera, ainda, que a atividade humana obedece a um sistema de relações instituído socialmente para atender a própria sociedade; logo, não tem nenhum sentido fora dessas relações estabelecidas, uma vez quea atividade é determinada pelas formas e meios da comunicação material e espiritual que são geradas pelo desenvolvimento das práticas de produção dos objetos sociais.

Trata-se, portanto, da atividade humana objetiva, que depende de seu lugar na sociedade, em suas condições de vida e cujo processo envolve ação, reflexão e significação, caracterizando assim uma relação triunívoca denominada por Vergani (1991) como sociedade-cognição-cultura, ou biunívoca na forma sociocognição-cultura.

As relações entre sociedade, cognição e cultura (onde se insere a Matemática, como uma prática sociocultural), constituem o foco central do pensamento de Teresa Vergani, presente nos livros $O$ zero e os infinitos: uma experiência de antropologia e Educação Matemática intercultural (1991) e Excrementos do sol: a propósito de diversidades culturais (1995). Nessas publicações Vergani coloca a Matemática em um patamar cultural originado no entrelaçamento social, cognitivo e cultural, como se constituísse em uma projeção tridimensional na qual os patrimônios humanos denominados cultura, sociedade e cognição operassem em múltiplas combinações de modo a originar informações explicativas, reflexivas e projetivas sobre a vida no planeta. 
Figura 1: Diagrama criado pelos autores

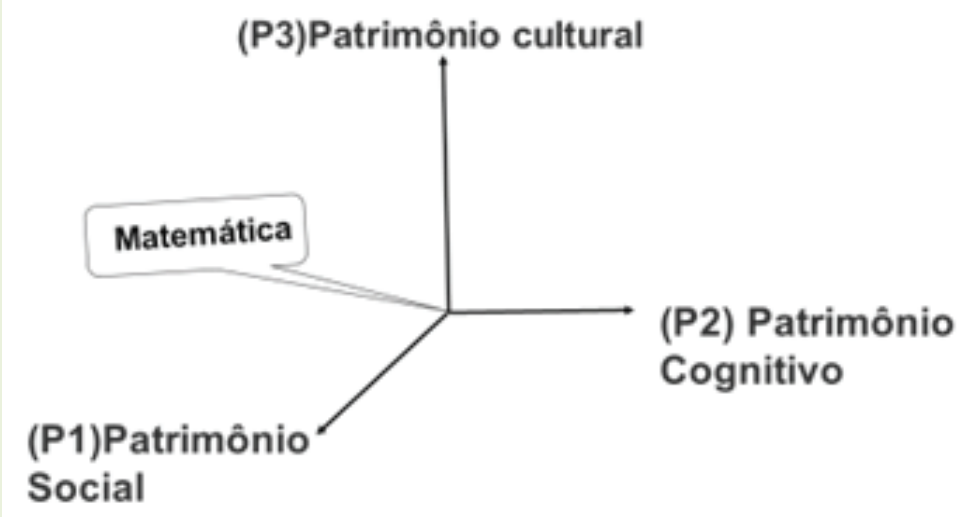

Ao observarmos o descritor da figura 1 perceberemos que nele estão implícitas relações explicativas estabelecidas pelos três tipos de patrimônios tomados como eixos de configuração dos objetos de estudos da matemática que, de acordo com cada elaboração podem caracterizar cada objeto em causa, sob enfoques simples ou conjugados, conforme suas especificações. Em cada situação, portanto temos uma representação do objeto de estudo, conforme a lente pela qual se lê esse objeto. O movimento de leitura dos objetos de interesse da matemática fez e continua fazendo gerar aspectos prioritários ou não nos estudos matemáticos focalizados na escola, nos diferentes níveis de ensino e na pesquisa sobre ensino de matemática e cultura matemática em seu sentido mais amplo.

Apoiados em Leontiev (1978), podemos admitir que essas múltiplas combinações para os exercícios de leituras da realidade se estabelecem

na cognição humana com base na suposição de que a base real (as atividades ou práticas sociais objetificadas) são incorporadas à personalidade humana na medida em que o agregado de suas relações com o mundo, que são sociais por natureza, porém relações que são realizadas, e são realizadas através de sua atividade, ou, mais precisamente, pelo agregado de suas atividades multifacetadas (LEONTIEV, 1978, p. 11).

Esse agregado das atividades multifacetadas humanas, operacionalizadas socialmente, de certo modo correspondem à busca de estabelecimento de um ambiente de sobrevivência e interação social, 
característico das culturas e da produção de conhecimento aberto, sem vinculação qualquer com o disciplinar, estabelecido pelo modelo de escola, como conhecemos. Nesse modelo de produção de pensamento, ação e linguagem, integrados entre si, não há espaços para pensar soluções isoladas para os problemas advindos das práticas socioculturais, e sim mediados por essas práticas e em favor delas.

Foi nessa fronteira entre o social, o cognitivo e o cultural que Vergani (1991; 1995) buscou estabelecer seus estudos e pesquisas para fundamentar uma epistemologia que sustentasse a relação entre sociedade, cognição e cultura como um pressuposto chave para instituir uma Educação Matemática operacionalizada por conexões entre as seguintes subáreas: matemática contextual; matemática sociocognição e cultura; estruturas do pensamento lógico-matemático; matemática, comunicação e aprendizagem; matemática e inteligibilidade do real; desenvolvimento do pensamento lógico-matemático; a matemática como linguagem universal; a matemática como expressão não verbal; informática; fundamentos de estatística aplicada à educação. Como concretizar essas relações na formação do professor de Matemática e nas ações educativas?

Em nossos estudos, alguns questionamentos focados foram os seguintes: 1) como explorar pedagogicamente uma prática sociocultural para potencializar o ensino de matemática na Educação Básica? Como podemos problematizar essas práticas de modo a potencializá-las no ensino de Matemática? A busca de respostas a essas questões teve como principal objetivo investigar como o estudo exploratório de uma prática sociocultural pode contribuir para a produção de problematizações que auxiliem o professor de Matemática nas atividades didáticas concretizadas na forma de Unidades Básicas de Problematização (UBPs). O que é uma UBP?

Para Miguel e Mendes (2010), uma prática social é social porque, mesmo quando é realizada por uma única pessoa, ela está sempre ligada as atividades humanas previamente desenvolvidas por comunidades socialmente organizadas. As problematizações propostas para a educação 
básica, a partir de uma prática investigada, tem um formato específico contemplado na proposta de Miguel e Mendes (2010), denominadas Unidades Básicas de Problematização (UBPs).

Para os autores, essa é uma etapa importante do trabalho de exploração das práticas socioculturais nas aulas de Matemática, pois pressupõe que os participantes devem ser organizados em grupos temáticos com o propósito de levantarem questões orientadoras que deverão envolver-se na investigação de práticas escolares mobilizadoras de cultura Matemática. Tais práticas podem ser de qualquer natureza: pedagógica, histórica, filosófica, epistemológica, lógica, sociológica, etc.

A proposta de produção de UBPs na formação do professor de Matemática pode ser uma opção didática que possibilite um melhor aproveitamento do processo de ensino e aprendizagem de Matemática com a finalidade de que a Educação Básica realmente forme o cidadão tornando-o crítico e agente ativo na transformação da sociedade.

Conforme salienta Leontiev (1972), para que tal transformação ocorra, se torna necessário considerar que é a atividade externa, desenvolvida pelo sujeito, em seu contexto social, que destrava o círculo de processos mentais internos, que o abre para o mundo objetivo. Para Leontiev $(1972$, p. 6),

a atividade de pessoas trabalhando juntas é estimulada por seus produtos, que, em primeiro lugar, correspondem diretamente às necessidades de todos os participantes. Mas a mais simples divisão técnica de trabalho que surge no processo, necessariamente leva ao surgimento de resultados parciais, intermediários, que são obtidos pela participação individual na atividade de trabalho coletiva, mas que por elas mesmas não podem satisfazer a necessidade de cada participante.

Assim, as práticas a serem estabelecidas na formação do professor de Matemática precisam ser fundamentadas em matrizes teórico-práticas que façam emergir princípios e processos nos quais se materializem situações contextuais e exercícios criativos que possam oportunizar a incorporação de aspectos sociocognitivos extraídos das práticas socioculturais cotidianas, 
conectadas às problematizações a serem estabelecidas nos momentos da aprendizagem matemática na escola.

Foi nesse sentido e com essa intenção que procuramos desenvolver uma pesquisa sobre algumas práticas socioculturais que oferecessem elementos para a exploração de situações contextuais, de modo a poder extrair delas as informações possíveis para elaboração de problematizações para o ensino de Matemática pelo professor quando do exercício da docência. Neste sentido, Leontiev (1972, p. 11) assegura que o processo de produção de conhecimento

\begin{abstract}
surge, originalmente, no sistema de relações objetivas nas quais ocorre a transição do conteúdo objetivo da atividade em seu produto. Mas, para este processo ser percebido, não é suficiente que o produto da atividade, tendo absorvido essa atividade, deve se apresentar ao sujeito como suas propriedades materiais; uma transformação deve ocorrer que o permita emergir como algo que o sujeito está ciente, isso quer dizer, em uma forma ideal. Essa transformação é afetada por meios da linguagem, que é o produto e meio de comunicação de pessoas ocorrendo na produção. A linguagem carrega em seus significados (conceitos) um certo conteúdo objetivo, mas um conteúdo completamente liberado de sua materialidade.
\end{abstract}

A linguagem e a comunicação são, portanto, os elementos essenciais para que seja possível conectar a atividade gerada nas práticas socioculturais às atividades a serem estabelecidas na escola como um meio de viabilizar a aprendizagem matemática na escola.

\title{
IMPLICAÇÕES EPISTEMOLÓGICAS E DIDÁTICAS
}

Se observarmos as práticas matemáticas sobre um enfoque P1P2 identificaremos que o mesmo denota uma face na qual emergem implicações referentes ao ensino de matemática na formação de professores e na educação básica que tratam, de forma individual e conjugada, dos dois enfoques: o social e o cognitivo, e que podem ser tomadas pelo professor e pelos pesquisador no sentido de estabelecer relações sociocognitivas advindas dessas práticas matemáticas, de modo a 
oferecer elementos de compreensão da matemática em suas dimensões sociocognitivas fundamentadas no exercício de um pensamento social acerca da matemática a ser ensinada e/ou aprendida.

Por outro lado podemos perceber que o enfoque P1P3 oferece um ambiente de identificação para refletirmos sobre possíveis implicações a respeito do ensino de matemática na formação de professores e na educação básica que explorem práticas matemáticas focalizadas sobre outros dois enfoques individuais ou conjugados: o social e o cultural, explorando possibilidades de ensino e de pesquisa que possam estabelecer relações socioculturais acerca dessas práticas matemáticas, para daí oferecer elementos de compreensão da matemática em suas dimensões socioculturais fundamentadas no exercício de um pensamento social e cultural acerca da matemática a ser ensinada e/ou aprendida.

Em um terceiro enfoque observamos a relação P2P3 na qual é possível refletir sobre suas implicações a respeito do ensino de matemática na formação de professores e na educação básica, bem como da pesquisa nesta área, que possa explorar práticas matemáticas em seus aspectos individuais tratando do cognitivo ou do cultural e que principalmente conjuguem os dois enfoques: o cognitivo e o cultural, para assim estabelece relações cognitivas que emergem das impregnações culturais acerca dessas práticas matemáticas ou seja nas enculturações matemáticas tal como sugere Alan Bishop (1999), de modo a oferecer elementos de compreensão da matemática em suas dimensões culturais cognitivas fundamentadas no exercício de um pensamento cultural acerca da matemática a ser ensinada e/ou aprendida.

Se considerarmos ainda as possibilidades de conexões entre P1P2 e PIP3 no que se refere à pesquisa e ao ensino de matemática na formação de professores e na educação básica, poderemos discutir sobre quais aspectos integrantes a matemática contextual poderá ter sua exploração e compreensão ampliada. Trata-se, portanto de uma dupla conjugação na qual as relações sociocognitivas e as socioculturais poderão contribuir mais 
largamente para a ampliação e fundamentação acerca das relações inter e multiculturais que constituem as práticas matemáticas e quais possibilidades poderão emergir dessas relações para a pesquisa e para $\circ$ ensino de matemática.

Outra relação duplamente conjugada e de extrema importância refere-se às conexões entre P1P2 e P2P3 na perspectiva de ampliar nossa compreensão acerca das relações sociocognitivas e culturais, que podem ser tratadas de forma integrada, fazendo emergir conexões que possibilitem uma perspectiva mais funda de nosso olhar sobre as práticas matemáticas pesquisadas e tomadas para abordar conteúdos referentes ao ensino de Matemática na formação de professores e na educação básica. O mesmo está implicado na dupla conexão entre P1P3 e P2P3 no que se refere a buscar na pesquisa um olhar mais ampliado e fundo acerca dos aspectos conceituais referentes ao ensino de Matemática na formação de professores e na educação básica.

Cabe-nos, entretanto, uma questão: como concretizar essas relações na formação do professor de Matemática e nas ações docentes na educação básica?

Algumas possibilidades para que essas relações possam se estabelecer apontam que será necessária a elaboração de um plano de ação para o exercício de identificação e descrição interpretativa dessas relações e conexões de práticas e saberes que originaram conhecimentos escolares para que se fundamente um ensino de matemática que provoque rupturas no paradigma vigente, como um desafio para o contexto regional, ou seja, como uma nova forma de construção da aprendizagem matemática sob uma perspectiva conjugada local-universal, baseada nos aspectos inter e multiculturais relacionados aos problemas investigados pela matemática acadêmica.

Para Bishop (1999) poderemos admitir enfoques isolados para a matemática se desconsiderarmos seu processo de enculturação ocorrido integradamente no envolvimento dos contextos cultural, societal (referentes 
aos grupos sociais em si), institucional, pedagógico e individual, pois é nas relações estabelecidas por esses cinco fatores intervenientes que o ensino de matemática poderá tratar de questões de ordem sociológica, ideológica, científica, tecnológica e afetiva. É nesse corpo de significados em que a matemática está imersa, sob um olhar dialógico, que considero a possibilidade de se ampliar a interpretação de códigos que contribuam para uma abordagem do ensino de matemática centrado nesses patamares epistemológicos: o loco-regional e o universal.

\section{O DESENVOLVIMENTO DA PESQUISA E SEUS ASPECTOS METODOLÓGICOS}

Em nossa pesquisa, selecionamos algumas práticas socioculturais dinamizadas no Rio Grande do Norte, como a arte da criação das rendas de bilro, as práticas ceramistas, a pesca, a agricultura, a criação de aves caipira, dentre outras atividades profissionais, de modo a poder caracterizálas na forma de um dossiê descritivo (etnográfico) e, a partir daí, oferecer a matéria-prima para a elaboração de propostas didáticas para as aulas de Matemática sob um enfoque interdisciplinar, a partir das realidades culturais investigadas (SILVA, 2013; 2014).

Nossa intenção foi, posteriormente: (1) organizar problematizações que envolvessem as práticas pesquisadas, para que pudéssemos orientar professores e estudantes de licenciatura em Matemática na exploração da realidade sociocultural como um processo de construção da matemática escolar centrada na relação sociedade-cognição-cultura; (2) realizar ações que promovam a interação entre alunos de graduação e pós-graduação na área de ensino de Matemática, bem como entre os professores da Educação Básica, por meio de estudos da realidade sociocultural como base para a elaboração de ações formativas materializadas, como seminários, colóquios ou cursos de curta duração; e (3) produzir dossiês etnográficos sobre as realidades sócio-históricas e culturais investigadas, bem como sobre as práticas sociais identificadas em cada contexto investigado, 
de modo a possibilitar a elaboração de novos materiais e atividades didáticas pelos professores da Educação Básica e pelos estudantes de licenciatura em Matemática (SILVA, 2013; 2014).

O método proposto para o desenvolvimento das ações investigativas pautou-se em uma perspectiva dialógica, de modo que todos os envolvidos pudessem participar das atividades investigativas, na forma de colaboração mútua, ou seja, em busca de uma produção coletiva, seguida por debates, depoimentos pessoais e esclarecimentos conjuntos. Ressaltou-se, ainda, a importância do registro de todas as informações possíveis durante os encontros, de modo a permitir o enriquecimento das discussões coletivas acerca dos temas emergentes durante a pesquisa.

Neste sentido, cada momento foi estruturado de acordo com os objetivos parciais a serem alcançados durante o processo de pesquisa, tendo em vista as contribuições que essa investigação pretende produzir para a formação de professores de matemática, foco central deste estudo.

Inicialmente, visitamos algumas escolas públicas da região metropolitana do município de Natal, Rio Grande do Norte, para sensibilizar os professores com a finalidade de organizar um grupo participante do projeto. Dessa primeira ação surgiram seis professores de matemática interessados. A partir desse momento, foram realizadas algumas entrevistas com esse grupo de professores para obter informações sobre suas práticas matemáticas na sala de aula, seus anseios, dificuldades e relações estabelecidas entre a matemática, a sociedade e a cultura, de modo a contribuir na ampliação de seus conhecimentos acerca do uso de práticas socioculturais em suas atividades docentes.

A partir das escutas dos professores de matemática sobre suas práticas e anseios, e com base nas relações verificadas entre os conteúdos matemáticos escolares e as práticas socioculturais características do Rio Grande do Norte, selecionamos alguns temas que envolvessem essas práticas que pudessem subsidiar uma pesquisa etnográfica a ser realizada, de modo a oferecer material bibliográfico para um exercício de 
problematização por parte dos professores envolvidos no trabalho. Neste sentido, realizamos, conjuntamente com o grupo de professores e com um bolsista de iniciação científica, uma seleção inicial de algumas práticas a serem investigadas, de modo a fazermos um levantamento destas, a fim de verificarmos algumas comunidades relacionadas a essas práticas e poder estabelecer um diálogo com essas comunidades e, assim, organizar um dossiê a ser utilizado nas etapas seguintes da pesquisa, principalmente nos trabalhos de problematização para o ensino de Matemática.

A partir do material referente às práticas socioculturais selecionadas, fizemos um levantamento bibliográfico sobre os assuntos de modo a subsidiar a elaboração de problematizações acerca das práticas socioculturais que poderiam ser exploradas no ensino de Matemática em uma etapa seguinte do projeto, junto aos professores da rede pública de ensino de Natal. Nesse sentido, foram realizadas sessões coletivas de estudos sobre os materiais bibliográficos pesquisados com a finalidade de compreender e reorganizar as descrições das práticas cotidianas pesquisadas, bem como as possibilidades de uso das mesmas na problematização a ser elaborada para o ensino de Matemática posteriormente. Nessas sessões, contamos com a participação do grupo de seis professores participantes da pesquisa, um bolsista de iniciação científica, um bolsista de Pós-doutorado Júnior (PDJ), do CNPq, e o coordenador da pesquisa.

Durante o período de estudo, organizamos uma primeira versão dos materiais levantados na pesquisa bibliográfica, em forma de produto impresso contendo as informações sistematizadas obtidas nos levantamentos e entrevistas realizadas sobre as práticas socioculturais investigadas. Todavia, em virtude de o tempo da pesquisa ter sido de apenas um ano, não foi possível concluir a organização e análise das informações obtidas durante a pesquisa etnográfica, com vistas a direcionar tais resultados organizados no sentido de apontar contribuições da pesquisa antropológica para formação dos professores de Matemática envolvidos no estudo. Como primeiro resultado do processo, organizamos uma versão preliminar do material 
pesquisado pelo grupo para que pudéssemos pensar na organização do trabalho formativo junto aos professores, bem como sua divulgação entre os envolvidos no projeto.

\section{RESULTADOS ALCANÇADOS, PRODUÇÃO OBTIDA E A SUA DIVULGAÇÃO}

Os resultados alcançados foram extremamente importantes para a nossa formação acadêmica, bem como para a formação inicial e continuada de professores que ensinam Matemática, uma vez que os materiais bibliográficos levantados na pesquisa foram de extremo valor para a elaboração da primeira versão de um dossiê sobre novas práticas socioculturais pesquisadas que estamos utilizando em outro projeto de pesquisa em andamento. Assim sendo, a pesquisa teve continuidade, como contribuição para a formação de professores que ensinam Matemática e para a comunidade de educadores matemáticos em geral.

As ações desenvolvidas e a produção gerada na pesquisa se constituíram em contribuições importantes para que os professores de Matemática em formação, envolvidos direta ou indiretamente no processo, possam refletir sobre a importância da utilização de práticas socioculturais na elaboração de problematizações matemáticas e situações didáticas que contribuam para a melhoria do ensino de Matemática.

A partir dos resultados obtidos durante a pesquisa, constatamos o grau de crescimento do grupo envolvido, bem como os níveis de contribuição das produções geradas no trabalho de todo o grupo. 0 material produzido foi organizado na forma de um dossiê com a finalidade de ser utilizado na problematização matemática na formação inicial e continuada de professores de matemática. Para a organização desse material, contamos com a participação de toda a equipe envolvida no projeto. Tais produções se materializaram em vários extratos, como apresentamos a seguir: 
Quadro 1: Extrato de práticas pesquisadas

\begin{tabular}{|l|l|}
\hline \multicolumn{1}{|c|}{ Temática pesquisada } & \multicolumn{1}{|c|}{ Local } \\
\hline Práticas artesanais que envolvem o uso de cabaças & Nordeste brasileiro \\
\hline $\begin{array}{l}\text { Práticas profissionais de fabricação e venda de farinha } \\
\text { de mandioca }\end{array}$ & Brejinho, RN \\
\hline $\begin{array}{l}\text { Práticas de fabricação e venda de peças de renda de } \\
\text { bilro }\end{array}$ & Nordeste brasileiro \\
\hline $\begin{array}{l}\text { Práticas profissionais de produção de peças decorativas } \\
\text { e utilitárias em cerâmica }\end{array}$ & $\begin{array}{l}\text { Norte e Nordeste do } \\
\text { Brasil }\end{array}$ \\
\hline $\begin{array}{l}\text { História da construção e restauração do forte dos Reis } \\
\text { Magos }\end{array}$ & Natal, RN \\
\hline Práticas profissionais de construção de cisternas & Rio Grande do Norte \\
\hline $\begin{array}{l}\text { História da construção dos açudes do Rio Grande do } \\
\text { Norte }\end{array}$ & Rio Grande do Norte \\
\hline $\begin{array}{l}\text { Práticas de construção e funcionamento das adutoras } \\
\text { no Rio Grande do Norte }\end{array}$ & Rio Grande do Norte \\
\hline
\end{tabular}

Fonte: Quadro elaborado pelos autores a partir do material pesquisado, 2015.

Para melhor exemplificar alguns dos aspectos explorados na organização do dossiê, mencionaremos, a seguir, trecho do levantamento documental realizado acerca da contrução de açudes no Rio Grande do Norte e sugestões de uso na formação de professores de matemática.

Temática: Sobre a construção e as capacidades hidrográficas de açudes e reservatórios do Rio Grande do Norte.

Sobre os açudes existentes no Rio Grande do Norte, Nordeste do Brasil, obtivemos informações de que a população pode ser abastecida somente com base em 37 desses, cuja capacidade nominal de armazenamento de água é superior a 1 milhão de metros cúbicos. No final do século XX, até mesmo esses açudes quase chegaram ao limite máximo de suas capacidades de utilização, o que equivale afirmar que os açudes médios aqueles considerados com capacidades de armazenamento entre 100.000 e 1.000.000 $\mathrm{m}^{3}$ - chegaram ao seu limite em alguns anos de seca do referido período (Cf. MELO, 2008, p. 76).

Ainda a esse respeito, Melo (2008) assegura que em geral os pequenos açudes são utilizados para abastecer áreas de demanda difusa - como 
fazendas, por exemplo - e se localizam, preferencialmente no interior das pequenas (com menos de 100 hectares de área). Além disso, a prática da açudagem na região, é bem antiga, pois desde os primórdios da colonização, a demanda rural é atendida preferencialmente, pela água acumulada nos pequenos açudes, nos anos de boas chuvas, ou seja, de bom inverno na região. Todavia, há alguns casos particulares em que o abastecimento ocorre com base em pequenos poços, cacimbas e, mais atualmente, por meio de cisternas, construídas em residências dos pequenos aglomerados da zona rural.

Um exemplo de açudagem é a barragem do açude Trairi. Localizada no município de Tangará, Rio Grande do Norte, o reservatório compreende um sistema complementar da bacia hidrográfica do referido município e cobre uma área de $1.580 \mathrm{~km}^{2}$. Tem como finalidades o abastecimento d'água de Tangará; o controle de cheias; a piscicultura e o aproveitamento das áreas de montante. Foi projetada e construída pelo Departamento Nacional de Obras contra as Secas (DNOCS). Os estudos preliminares previam uma barragem em concreto armado. Sua construção teve início em fevereiro de 1949 e foi concluída em julho do mesmo ano. Praticamente no término do levantamento da bacia hidráulica foi encontrado outro local para a construção de uma barragem de terra, propiciando mais capacidade de armazenamento e maior economia que a alternativa estudada anteriormente. Os estudos para este segundo local da barragem do Trairi foram iniciados no fim de julho de 1949 e concluídos no final de dezembro do mesmo ano.

O vertedouro é de superfície livre, escavado em rocha até a cota 110,50. Formado por um canal retangular, está localizado na ombreira direita da barragem. Dois muros laterais foram construídos em concreto armado para proteção da ombreira e da barragem. A tomada d'água é composta de uma torre em concreto armado, na qual estão instalados os equipamentos de manobra de duas comportas retangulares, a galeria é de seção retangular, também em concreto armado. 
Figura 2: Seção longitudinal da planta do açude

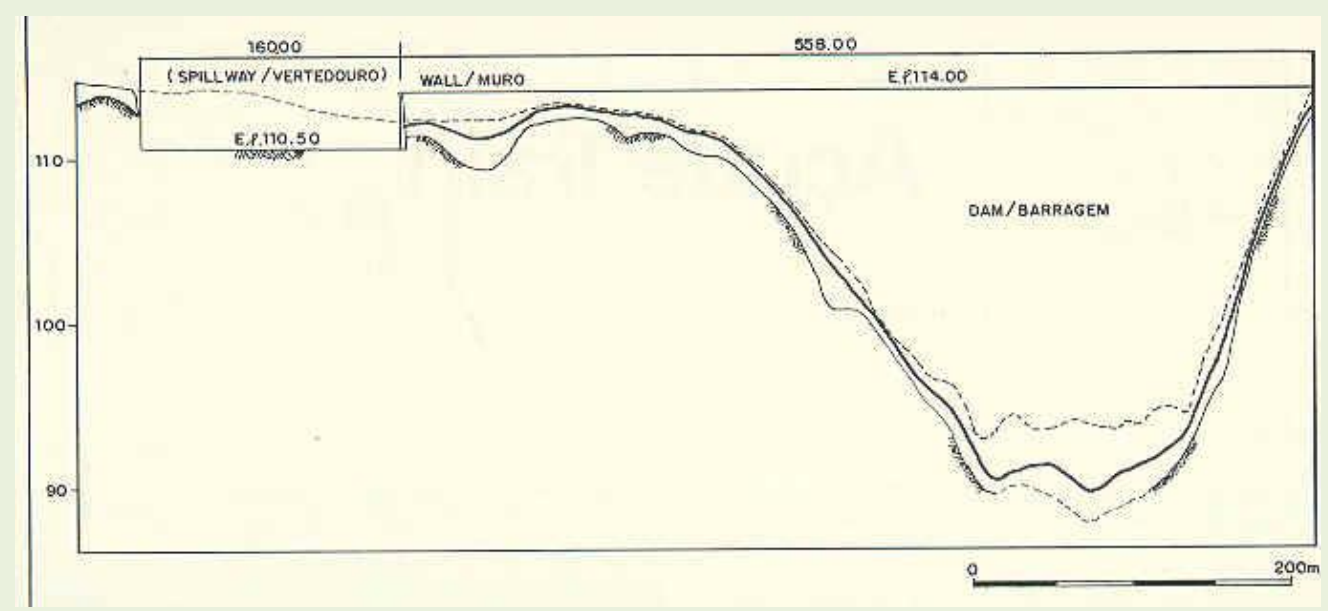

Fonte: DNOCS, 2014.

O regime das chuvas foi obtido por meio dos dados das estações pluviométricas localizadas na bacia hidrográfica do açude. As vazões de projeto foram determinadas com o emprego das fórmulas empíricas do Engenheiro Francisco Aguiar. Em 1954, em virtude de intensas chuvas ocorridas na região, a barragem do Trairi foi submetida a severas condições de trabalho, com lâminas de sangria atingindo alturas superiores às previstas no projeto, acrescidas pelo arrombamento de açudes públicos e particulares existentes na sua bacia de captação.

Figura 3: Seção transversal à barragem

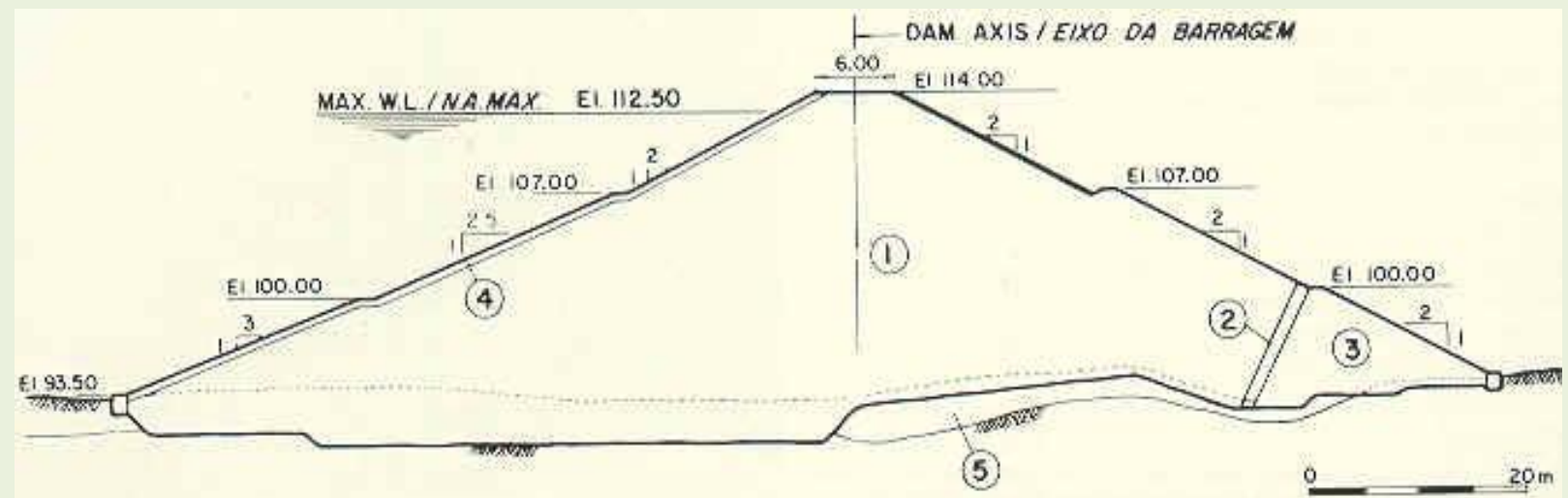

Fonte: DNOCS, 2014. 
Figura 4: Seção transversal à barragem após o extravasamento

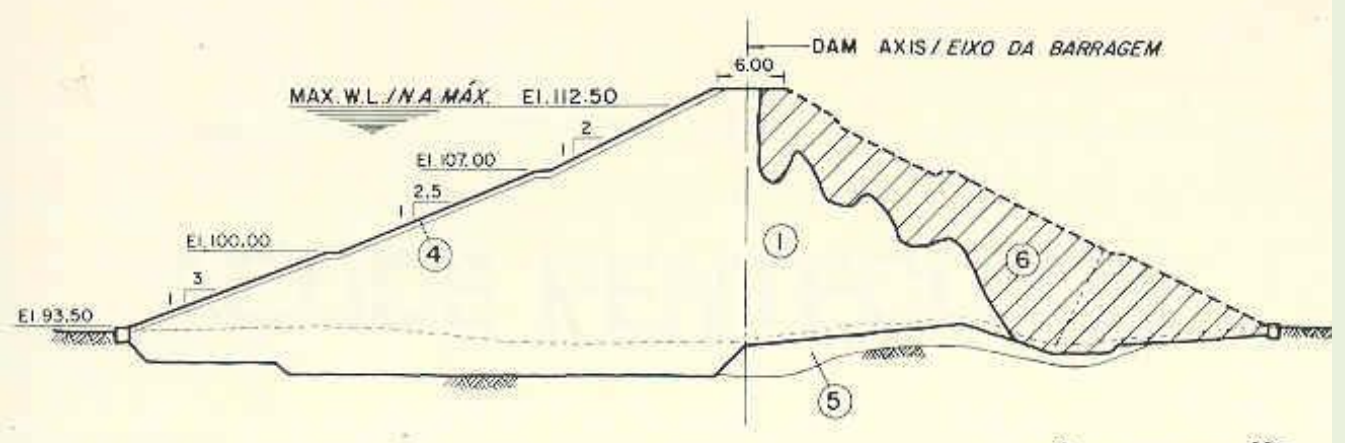
(1) CLAYEY SILT
SILTE ARGLOSO
(4) CEMENTEO HAND PLACED RIP-RAP
(2) TRANSITION LAYERS
CAMADAS DE TRANSKAÖO
(5) SAND
(3) ROCKFILL
ENROCAMENTO
(6) ERODEO MATERIAL
MATERIAL ERODIWO

Fonte: DNOCS, 2014.

Quadro 2: Características Técnicas da região da construção

\begin{tabular}{|c|c|c|c|}
\hline Capacidade & $35.230 .000 \mathrm{~m}^{3}$ & $\begin{array}{l}\text { Comprimento pelo } \\
\text { coroamento }\end{array}$ & $638 m$ \\
\hline Localização & Tangará-RN & Largura do coroamento & $6 m$ \\
\hline Sistema & Complemento & Volume do maciço & $270.00 \mathrm{~m}^{3}$ \\
\hline Rio & Trairi & Vertedouro & \\
\hline Bacia hidrográfica & $1.580 \mathrm{~m}^{2}$ & Tipo & $\begin{array}{l}\text { Descarga } \\
\text { Livre }\end{array}$ \\
\hline Bacia hidráulica & 657ha & Lâmina máxima prevista & $2 m$ \\
\hline $\begin{array}{c}\text { Precipitação média } \\
\text { anual }\end{array}$ & $470 \mathrm{~mm}$ & Largura & $160 \mathrm{~m}$ \\
\hline $\begin{array}{l}\text { Coeficiente de } \\
\text { escoamento }\end{array}$ & $5,72 \%$ & Revanche & $3,50 \mathrm{~m}$ \\
\hline $\begin{array}{l}\text { Volume afluente } \\
\text { anual }\end{array}$ & $8.079 .300 \mathrm{~m}^{3}$ & Tomada d'água & \\
\hline Descarga máxima & $541,03 \mathrm{~m}^{3}$ & Seção da galeria & $\begin{array}{l}1,20 x \\
1,50 m\end{array}$ \\
\hline Barragem & & Extensão da galeria & $60 m$ \\
\hline Tipo & $\begin{array}{l}\text { Terra } \\
\text { Homogênea }\end{array}$ & $\begin{array}{c}\text { Dimensões da comportas } \\
\text { (2) }\end{array}$ & $\begin{array}{l}0,90 x \\
1,50 \mathrm{~m}\end{array}$ \\
\hline Altura máxima & $27 \mathrm{~m}$ & & \\
\hline
\end{tabular}

Fonte: DNOCS, 2014. 
A partir das informações apresentadas anteriormente, o professor pode desenvolver o trabalho na forma de elaboração de uma UBP, da seguinte maneira:

1. Lançar desafios aos seus alunos para que levantem questões acerca das temáticas disciplinares e não disciplinares que envolvem o tema;

2. Propor a elaboração de problematizações matemáticas que envolvam medidas de capacidade, relações métricas a serem estabelecidas na exploração da geometria do terreno, a partir das imagens apresentadas, e sugerir que façam uma pesquisa ampliada sobre o assunto;

3. Solicitar que verifiquem informações acerca da média de consumo de água na região e das relações desse consumo com a capacidade hidrográfica do açude, bem como sobre a distribuição da água desse açude pelas microrregiões do Rio Grande do Norte, que estão próximas desse reservatório;

4. Requerer que esbocem modelos matemáticos possíveis que envolvam a relação entre o índice pluviométrico da região e o volume de água a ser acumulado no reservatório no sentido de prever o seu transbordamento em caso de muitas chuvas ou a falta de água na região, em caso de seca;

5. Sugerir a criação de pequenos documentários sobre o assunto, envolvendo a contextualização das informações pesquisadas e depoimentos de autoridades e moradores locais, de modo que esse material elaborado possa ser utilizado nas escolas da região;

6. Propor a elaboração de maquetes que envolvam a representação concreta dessa temática como um material didático a ser explorado de maneira problematizadora na sala de aula do ensino fundamental e médio. 


\section{CONSIDERAÇÕES FINAIS}

Os resultados da pesquisa foram extremamente importantes para os professores envolvidos direta ou indiretamente no projeto, bem como para estudantes da Educação Básica e ainda para os futuros professores de matemática, além da comunidade de educadores matemáticos em geral.

Nossa afirmação está apoiada no fato de que os produtos gerados na pesquisa como, por exemplo, o levantamento bibliográfico de informações relacionadas às práticas socioculturais e profissionais que podem subsidiar a elaboração de dossiês a serem utilizados na elaboração de problematizações para uso pedagógico, tanto na formação de professores de Matemática como para incrementar as ações docentes na Educação Básica, principalmente para a superação das dificuldades conceituais e didáticas dos professores no exercício da docência, poderão contribuir para que os professores avancem criativamente na sua prática de sala de aula.

Neste sentido, os resultados obtidos deixaram evidente que houve um aumento significativo no grau de crescimento do grupo envolvido, com relação à superação das suas dificuldades conceituais ao se envolverem no levantamento bibliográfico, nas leituras e discussões temáticas, bem como na vivência ao explorar as práticas realizadas em diversas comunidades para, assim, perceberem a possibilidade de usar essas práticas no ensino de Matemática.

Assim as reflexões estabelecidas a partir da avaliação de cada momento da pesquisa nos levou a conceber a continuidade do trabalho, tendo em vista a necessidade de produção de outros materiais didáticos e atividades que possam contribuir para a melhoria do trabalho de professor, como o aperfeiçoamento na organização do material pesquisado sobre as práticas sociais investigadas, de modo que ele seja incorporado ao trabalho do professor em sala de aula, e fora dela, como material problematizador e direcionador dos estudos de temas matemáticos, bem como em uma perspectiva complementar na abordagem dos tópicos matemáticos 
tratados no ensino fundamental e médio. Espera-se que ele ajude a construir um trabalho efetivo de problematização e que estimule a construção conceitual dos estudantes de licenciatura em Matemática e na Educação Básica.

Com base no material pesquisado, foi realizado um curso de formação continuada de professores com a participação de docentes da rede pública de ensino de Natal, tendo em vista ampliar o diálogo entre escola e universidade, já iniciado. Com isso, podermos elaborar, executar e avaliar um trabalho coletivo de planejamento, acompanhamento e reorientação das práticas dos professores de Matemática durante seu exercício docente.

\section{REFERÊNCIAS}

AÇUDE TRAIRI. DESCRIÇÃO GERAL. In:

<http://www.dnocs.gov.br/dnocs/doc/canais/barragens>. Acesso em: 02 set. 2014.

ALMEIDA, M. da C. Complexidade, saberes científicos, saberes da tradição. São Paulo: Ed. Livraria da Física, 2010 (Col. Contextos da Ciência).

BISHOP, A. J. Enculturación matemática. La educación matemática desde una perspectiva cultural. Trad. Genís Sánchez Barberán. Barcelona, Espanha: Paidós, 1999.

DNOCS. 1. DERUR. Arquivo Técnico. Processos do Açude Pul. Santa Cruz do Trairi S.n.T.

FARIAS, C. A. Alfabetos da alma: histórias da tradição na escola. Porto Alegre: Sulina, 2006.

FARIAS, C. A.; MENDES, I. A. As culturas são as marcas das sociedades humanas. In: MENDES, I. A.; FARIAS, C. A. (Org.). Práticas socioculturais e Educação Matemática. São Paulo: Ed. Livraria da Física, 2014, p. 15-48 (Col. Contextos da Ciência).

LEONTIEV, A. O homem e a cultura. In: LEONTIEV, A. Desenvolvimento do Psiquismo. Lisboa: Livros Horizonte, 1979.

LEONTIEV, A. Actividade, consciência e personalidade (1978). In: <https://www.marxists.org/>. Acesso em: 03 mar. 2016.

LEONTIEV, A. Atividade e Consciência. In: <https://www.marxists.org/>. 1972. Acesso em: 03 mar. 2016.

MELO, G. D. de. Planejamento dos recursos hídricos da bacia hidrográfica do rio Seridó, no Rio Grande do Norte. Dissertação. Mestrado. Programa de Pós- 
graduação em Engenharia Sanitária. Natal: Universidade Federal do Rio Grande do Norte, 2008.

MENDES, I. A.; FARIAS, C. A. (Org.). Práticas socioculturais e Educação Matemática. São Paulo: Ed. Livraria da Física, 2014 (Col. Contextos da Ciência).

MIGUEL, A.; MENDES, I. A. Mobilizing histories in mathematics teacher education: memories, social practices, and discursive games.In: ZDM Mathematics Education (2010) 42:381-392.

MORIN, E. O método III. O conhecimento do conhecimento. 2. ed. Trad. Maria Gabriela de Braganca. Lisboa: Europa-América, 1996.

RIBEIRO, D. O povo brasileiro. São Paulo: Companhia das Letras, 1995.

SILVA, C. A. F. Estudos sobre cultura e práticas sociais: contribuições para formação de professores de matemática. Projeto de pesquisa de Pósdoutorado Júnior. Conselho Nacional de Desenvolvimento Científico e Tecnológico (CNPq). Natal, 2013.

SILVA, C. A. F. Estudos sobre cultura e práticas sociais: contribuições para formação de professores de matemática. Relatório de pesquisa de Pósdoutorado Júnior. Conselho Nacional de Desenvolvimento Científico e Tecnológico (CNPq). Natal, 2014.

SNOW, C. P. As duas culturas e uma segunda leitura. Trad. Geraldo Gerson de Souza. São Paulo: EDUSP, 1995.

VERGANI, T. Excrementos do sol. A propósito de diversidades culturais. Lisboa: Pandora, 1995 (Olhos do Tempo).

VERGANI, T. O zero e os infinitos. Uma experiência de Antropologia e Educação Matemática intercultural. Lisboa: Minerva, 1991.

Recebido em: Março de 2017

Aceito em: Abril de 2017 